\title{
Gastrointestinal parasites of dromedary camel (Camelus dromedarius) in Algeria
}

\author{
Messaoud Bouragba1,2 (D), AbdElkarim Laatamna² (D), Fatima Elzahra Cheddad ${ }^{3}$, Djamel Baroudi \\ Karim Houali ${ }^{1}$ and Ahcène Hakem ${ }^{2,5}$
}

1. Laboratory of Analytical Biochemistry and Biotechnology, Faculty of Biological and Agronomical Sciences, University of Mouloud Mammeri, Tizi-Ouzou, Algeria; 2. Laboratory of Exploration and Valorization of Steppic Ecosystems, Faculty of Nature and Life Sciences, University of Djelfa, Djelfa, Algeria; 3. Laboratory of Biomedical Analyses, Djelfa, Algeria;

4. Higher National Veterinary School, Issad Abbes Street, Algiers, Algeria; 5. Centre Research in Agro-Pastoralism, Djelfa, Algeria.

Corresponding author: Messaoud Bouragba, e-mail: biomessaoud@gmail.com

Co-authors: AKL: laatamnaabdelkarim@yahoo.com, FEC: cheddadaicha@gmail.com, DB: dbaroudi7@hotmail.com, KH: houalitizi@yahoo.fr, AH: ahcenehakem@gmail.com

Received: 31-03-2020, Accepted: 29-06-2020, Published online: 19-08-2020

doi: www.doi.org/10.14202/vetworld.2020.1635-1640 How to cite this article: Bouragba M, Laatamna AK, Cheddad FE, Baroudi D, Houali K, Hakem A (2020) Gastrointestinal parasites of dromedary camel (Camelus dromedarius) in Algeria, Veterinary World, 13(8): 1635-1640.

\begin{abstract}
Aim: The present study was designed to investigate the prevalence and identification of gastrointestinal parasites in feces samples of dromedary camels (Camelus dromedarius) in Algeria based on microscopic examination.

Materials and Methods: A total of 717 fresh fecal samples obtained from 28 farms at Steppe and Northern Sahara regions of Algeria were processed for microscopic examination after concentration by formalin-ether sedimentation and flotation techniques. In addition, microscopic examination of Cryptosporidium spp. was done by modified Ziehl-Neelsen staining and Lugol staining procedure was used for the detection of Giardia cysts.

Results: Microscopic examination indicated an infection rate of gastrointestinal parasites of 48.26\% (346/717). Protozoan infections were recorded at $17.02 \%$ (122/717), whereas helminth infections were recorded at $23.71 \%(170 / 717)$. In addition, mixed infection (protozoans and helminths) was seen at 7.53\% (54/717). No correlation was found between infection and age of the animals, nor the consistency of the stool samples; in addition, neither influence of sex nor breed of camels was observed. Eighteen genera of gastrointestinal parasites were revealed; including four genera of protozoa, 12 Nematoda, one Cestoda, and one Trematoda. Strongyloides spp. and Eimeria spp. showed the highest rate of parasitism, while Cooperia spp. was observed with the lowest prevalence. Cryptosporidium spp. was detected in 13 among 717 examined samples (1.81\%).

Conclusion: The parasite fauna infecting the gastrointestinal tract of the Algerian dromedary is much diversified. The detected parasites in camels are similar to counterparts in other ruminants, posing serious challenge to animal farming. Future studies should be carried out to better understand the epidemiology of these parasitic diseases and their economic and public health impact.
\end{abstract}

Keywords: Algeria, camel dromedary, helminths, prevalence, protozoans.

\section{Introduction}

Historically, camels are important animals for their meat and milk production as well as transportation, especially across deserts in many African and Asian countries. However, they are prone to infection by many parasitic diseases [1-5] resulting in considerable economic losses related to decrease in productivity and performance as well as mortality in severe cases $[5,6]$.

Gastrointestinal parasites, including protozoa and helminths, are common findings in camel populations in different countries [2,7-10]. In Algeria, the camel farming sector (354.465 camel heads) has a

Copyright: Bouragba, et al. Open Access. This article is distributed under the terms of the Creative Commons Attribution 4.0 International License (http://creativecommons.org/licenses/ by/4.0/), which permits unrestricted use, distribution, and reproduction in any medium, provided you give appropriate credit to the original author(s) and the source, provide a link to the Creative Commons license, and indicate if changes were made. The Creative Commons Public Domain Dedication waiver (http:// creativecommons.org/publicdomain/zero/1.0/) applies to the data made available in this article, unless otherwise stated. substantial contribution to cover the growing gap in protein and dairy products. However, camel farming suffers from many debilitating diseases, including vector-borne and blood infections such as babesiosis, rickettsiosis, and trypanosomosis [11-13] as well as tissue dwelling parasites such as Echinococcus spp. $[14,15]$. Notwithstanding, little is available on the gastrointestinal parasitic infections in dromedary camels in Algeria [16,17].

The present study was designed to investigate the prevalence and identification of gastrointestinal parasites in camels in Algeria based on the microscopic examination. To this end, fecal samples collected from dromedary camels at Steppe and Northern Sahara regions of Algeria were investigated using the coproscopic examination.

\section{Materials and Methods}

\section{Ethical approval and informed consent}

The study protocol was approved by the Laboratory of Exploration and Valorization of Steppic 
Ecosystems, Faculty of Nature and Life Sciences, University of Djelfa. Informed written consent was obtained from farm owners or managers. Camels were handled in compliance with the established regulations and guidelines in Algeria.

\section{Study area}

This study was carried out between March 2015 and July 2018 on 28 camel herds in M'sila and Djelfa provinces at the steppe region in the central part of Northern Algeria; as well as Biskra and Laghouat in the Northern part of the Algerian Sahara (Figure-1). Djelfa and M'sila regions are generally dominated by a semi-arid climate (low and irregular precipitation) with an average annual temperature during the study period of $15.7{ }^{\circ} \mathrm{C}$ and $19.2{ }^{\circ} \mathrm{C}$ respectively. While Biskra and Laghouat are dominated by arid climate with an average annual temperature of $23.3{ }^{\circ} \mathrm{C}$ and $19.8^{\circ} \mathrm{C}$, respectively. One feature worth mentioning, the northwestern part of the Laghouat region is characterized during the winter by snowfall and strong periods of frost. Camels graze on pasture during most of the year. The study area (either the steppe region or Northern part of the Algerian Sahara has extensive small ruminant (sheep and goat) farming activity.

\section{Sample collection}

A total of 717 fecal samples were obtained from camels either directly from their rectum or from the ground immediately after defecation. Each sample was individually placed into a sterile plastic container, labeled with the epidemiological data, and transported in an isotherm box to the laboratory.

\section{Coprological examination}

The samples were subjected to macroscopic examination to assess the consistency of the feces and to check for visible parasitic elements. Fecal samples were processed for microscopic examination after concentration by formalin-ether sedimentation [18]. In addition, all samples were processed by floatation technique ( $\mathrm{NaCl}$ solution of 1.2 density). The microscopic examination of Cryptosporidium spp. was done by modified Ziehl-Neelsen staining procedure [19] and Lugol staining procedure was used

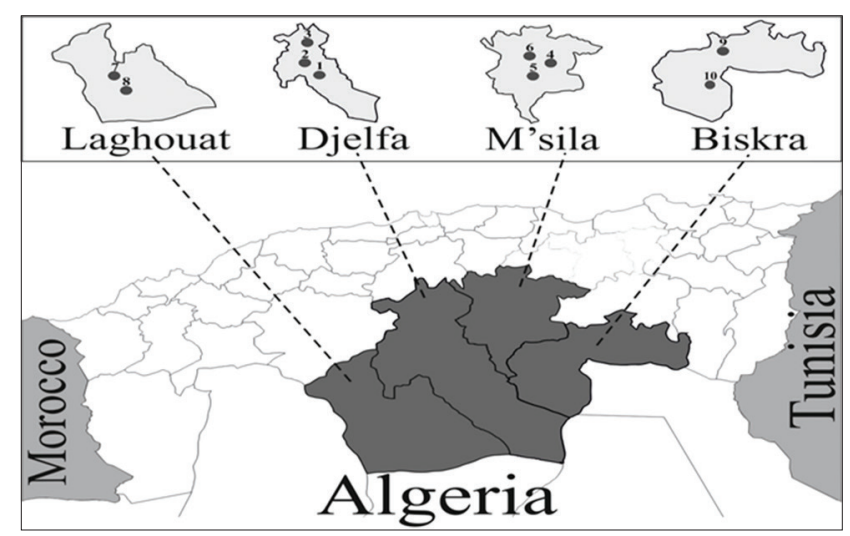

Figure-1: Map of Algeria showing the locations of examined herds of dromedary camel in the steppe (Djelfa, M'sila) and Northern Saharan (Laghouat, Biskra) regions. for the detection of Giardia cysts. Genus identification was carried out based on the detection of eggs and oocysts excretion in the feces; no adult or larval stages (for helminths) were used to determine the type of parasite.

To study the degree of infestation of Cryptosporidium spp. oocysts, a scoring system for positive specimens can be used based on a semi-quantitative technique. Under the $\times 40$ objective, the number of oocysts was calculated in 200 fields per slide on average. However, this technique cannot be considered an accurate quantitative measurement because the number of oocysts changes considerably during the course of infection. The score for each positive slide was established as follows: $(+)$ less than 5 oocysts per slide, $(++) 1$ to 10 oocysts per field of view, and $(+++)$ 11 or more oocysts per field of view [20].

\section{Statistical analysis}

Excel software was used to perform the statistical analysis. The Chi-square test was exploited to assess relationships between the parasitism rate and animal attributes (age, sex, breed, and presence or absence of diarrhea). The confidence interval was fixed at $95 \%$ and the Chi-square value was calculated with $\mathrm{p}<0.05$ which was considered as statistically significant.

\section{Results}

The microscopic examination revealed an overall infection rate of $48.26 \%$ (346/717). Infected camels were found to be harboring eggs or oocysts at least one genus of gastrointestinal parasites. The parasitic infection was recorded in all examined farms (Table-1).

From the 346 positive cases, 239 (33.33\%) were those with single infection, i.e., each animal was infected only by one parasite type. The other infections were multiple (either double, triple, or quadruple with infection cases of 82, 21, and 3, respectively). In addition, one 9-month-old camel was found to be infected by five genera of parasites.

Protozoan infections were observed in 122/717 cases $(17.02 \%)$, whereas helminth infections were observed in 170/717 (17.02\%) camels. In addition, mixed infections of protozoan and helminth were recorded in 54/711 (7.53\%) animals. Occurrence of infection was similar in female and male camels $(242 / 508 ; 47.64 \%)$ for the former, and (104/209; $49.76 \%$ ) for the latter. Furthermore, no correlation was found between infection and age of the animals, nor the consistency of the stool samples (presence or absence of diarrhea). Neither breed of the camels nor area had influence on the infection rate (Table-2).

Cryptosporidium spp. was detected in four localities (Table-1) with an overall prevalence of $1.81 \%$ (13/717). Cryptosporidium excretion did not vary significantly by sex, nor breed, or origin region. Out of 20 diarrheic camels, only one animal showed Cryptosporidium spp. excretion. Therefore, this 
Table-1: Overall infection rate in dromedary farms sampled from the Steppe and Northern Saharan regions.

\begin{tabular}{|c|c|c|c|c|c|c|c|}
\hline \multirow[t]{2}{*}{ Province } & \multirow[t]{2}{*}{ Locality } & \multirow{2}{*}{$\begin{array}{l}\text { Sampled } \\
\text { herds }\end{array}$} & \multirow{2}{*}{$\begin{array}{c}\text { Examined } \\
\text { camels }\end{array}$} & \multicolumn{2}{|c|}{ Overall infection } & \multicolumn{2}{|c|}{ Cryptosporidium spp. } \\
\hline & & & & $\mathbf{n}$ & Prevalence (\%) & $\mathbf{n}$ & Prevalence (\%) \\
\hline \multirow[t]{3}{*}{ Djelfa } & Musrane $^{1}$ & 7 & 188 & 86 & 45.74 & 5 & 2.66 \\
\hline & Zaafrane $^{2}$ & 3 & 55 & 31 & 56.36 & 0 & 0 \\
\hline & Boughezoul $^{3}$ & 6 & 165 & 93 & 56.36 & 4 & 2.42 \\
\hline \multirow[t]{3}{*}{ M'sila } & Maarif ${ }^{4}$ & 4 & 87 & 44 & 50.57 & 3 & 2.91 \\
\hline & Zerarga $^{5}$ & 1 & 19 & 1 & 5.26 & 0 & 0 \\
\hline & Bainou $^{6}$ & 1 & 16 & 12 & 75.0 & 0 & 0 \\
\hline \multirow[t]{2}{*}{ Laghouat } & Tadjmout $^{7}$ & 1 & 15 & 5 & 33.33 & 0 & 0 \\
\hline & Berkane $^{8}$ & 1 & 56 & 26 & 46.43 & 0 & 0 \\
\hline \multirow[t]{2}{*}{ Biskra } & Toulga $^{9}$ & 3 & 103 & 40 & 38.83 & 1 & 0.97 \\
\hline & Sidi Khaled ${ }^{10}$ & 1 & 13 & 8 & 61.54 & 0 & 0 \\
\hline Total & 10 & 28 & 717 & 346 & 48.26 & 13 & 1.81 \\
\hline
\end{tabular}

${ }^{1-10}$ Correspond to the localities shown in Figure-1

Table-2: Distribution of the parasitism rate by sex, age, presence or absence of diarrhea, breed, and area.

\begin{tabular}{|c|c|c|c|c|c|}
\hline \multirow[t]{2}{*}{ Variable } & \multirow{2}{*}{$\begin{array}{l}\text { Examined } \\
\text { camels }\end{array}$} & \multicolumn{2}{|c|}{ Overall infection } & \multicolumn{2}{|c|}{ Cryptosporidium spp. } \\
\hline & & $\mathbf{n}$ & Prevalence (\%) & $\mathbf{n}$ & Prevalence (\%) \\
\hline \multicolumn{6}{|l|}{ Gender } \\
\hline Male & 209 & 104 & 49.76 & 3 & 1.44 \\
\hline Female & 508 & 242 & 47.64 & 10 & 1.97 \\
\hline$\chi^{2}(p$-value $)$ & & \multicolumn{2}{|c|}{$0.267(0.605)$} & \multicolumn{2}{|c|}{$0.236(0.627)$} \\
\hline \multicolumn{6}{|l|}{ Age } \\
\hline$<1$ years & 279 & 138 & 49.46 & 3 & 1.08 \\
\hline $1-4$ years & 181 & 92 & 50.83 & 9 & 4.97 \\
\hline 4-9 years & 182 & 81 & 44.51 & 1 & 0.55 \\
\hline$>9$ years & 75 & 35 & 46.67 & 0 & 0 \\
\hline$\chi^{2}(p-v a l u e)$ & & \multicolumn{2}{|c|}{$1.744(0.627)$} & \multicolumn{2}{|c|}{$14.02(0.009)$} \\
\hline \multicolumn{6}{|l|}{ Diarrhea } \\
\hline Presence & 20 & 9 & 45.00 & 1 & 5.00 \\
\hline Absence & 697 & 337 & 48.35 & 12 & 1.72 \\
\hline$\chi^{2}(p$-value $)$ & & \multicolumn{2}{|c|}{$0.087(0.768)$} & \multicolumn{2}{|c|}{$1.174(0.279)$} \\
\hline \multicolumn{6}{|l|}{ Breed } \\
\hline Ouled-Nail & 314 & 149 & 47.45 & 5 & 1.59 \\
\hline Sidi-Cheik & 122 & 56 & 45.90 & 3 & 2.46 \\
\hline Chaambi & 204 & 102 & 50.00 & 5 & 2.45 \\
\hline Reguibi & 77 & 39 & 50.65 & 0 & 0 \\
\hline$\chi^{2}(p$-value $)$ & & \multicolumn{2}{|c|}{$0.739(0.864)$} & \multicolumn{2}{|c|}{$2.260(0.520)$} \\
\hline \multicolumn{6}{|l|}{ Area } \\
\hline Steppe (Semi-arid) & 530 & 267 & 50.38 & 12 & 2.26 \\
\hline North. Sahara (Arid) & 187 & \multirow{2}{*}{\multicolumn{2}{|c|}{$\begin{array}{l}79 \\
3.660(0.056)^{42.25}\end{array}$}} & 1 & 0.53 \\
\hline$\chi^{2}(p$-value $)$ & & & & \multicolumn{2}{|c|}{$2.322(0.128)$} \\
\hline Total & 717 & 346 & 48.26 & 13 & 1.81 \\
\hline
\end{tabular}

presence was not significantly associated with diarrhea. However, a significant difference $(\mathrm{p}=0.009)$ was observed between the presence of Cryptosporidium spp. and age of examined camels. The higher rate of infection $(9 / 181 ; 4.97 \%)$ was recorded in animals aged between 1 and 4 years, while no infection was recorded for animals older than 9 years (Table-2). Among infected camels (13 cases), nine positive cases showed Cryptosporidium excretion with a mean score $(<5$ oocysts/slide). Meanwhile, two infected camels showed a middle score (1-10 oocysts/field of view). There were no positive cases where the number of oocysts is more than 11 oocysts per field of view (Table-3).

The results showed that many parasitic classes infect dromedary camel. The highest rate was $21.76 \%$ (156/717 were infested with Nematoda parasites);
Trematoda was the lowest at $0.28 \%$ (Table-4). In total, 18 genera of gastrointestinal parasites were recorded in the present investigation; including four genera of protozoa and 14 ones of helminthes (12 Nematoda, one Cestoda and one Trematoda). Strongyloides spp. (11.16\%) and Eimeria genus (10.32\%; data not shown) showed the highest rate of parasitism. In addition, Eimeria oocysts were identified as Eimeria cameli (14 cases; 1.95\%), Eimeria dromedarii (37 cases; 5.16\%), and there main as Eimeria spp. (23 cases; 3.21\%), while, Cooperia spp. was lowest in prevalence with two cases $(0.28 \%)$ (Table-5).

\section{Discussion}

Little is known about epidemiology of gastrointestinal parasitic infections in dromedary camels in Algeria. The results of the present study indicated 
Table-3: Degree of infestation by Cryptosporidium spp. oocysts in dromedary camel.

\begin{tabular}{lcccc}
\hline & Total & \multicolumn{3}{c}{ Degree of infestation } \\
\cline { 2 - 5 } & 13 & $\begin{array}{c}\mathbf{1 - 5} \\
\text { oocysts } \\
(+)\end{array}$ & $\begin{array}{c}\mathbf{1 - 1 0} \\
\text { oocysts } \\
(++)\end{array}$ & $\begin{array}{c}\text { >10 } \\
\text { oocysts } \\
(+++)\end{array}$ \\
\hline $\begin{array}{l}\text { Number of } \\
\text { infected camels }\end{array}$ & 11 & 2 & 0 \\
\hline
\end{tabular}

Table-4: Infection rate of identified categories gastrointestinal parasites in examined camels.

\begin{tabular}{lcc}
\hline $\begin{array}{l}\text { Identified } \\
\text { parasites }\end{array}$ & $\begin{array}{c}\text { Number of } \\
\text { infested camels }\end{array}$ & $\begin{array}{c}\text { Prevalence } \\
(\%)\end{array}$ \\
\hline Protozoa & 122 & 17.02 \\
Nematoda & 156 & 21.76 \\
Cestoda & 12 & 1.67 \\
Trematoda & 2 & 0.28 \\
Mixed infection & 54 & 7.53 \\
Total & 346 & 48.26 \\
\hline
\end{tabular}

Table-5: Infection rate of identified genera of gastrointestinal parasites in examined camels.

\begin{tabular}{lcc}
\hline Identified parasites & $\begin{array}{c}\text { Number of } \\
\text { infested camels }\end{array}$ & $\begin{array}{c}\text { Prevalence } \\
(\%)\end{array}$ \\
\hline Protozoa & 23 & 3.21 \\
Eimeria spp. & 14 & 1.95 \\
Eimeria cameli & 37 & 5.16 \\
Eimeria dromedarii & 54 & 7.53 \\
Neobalantidium spp. & 50 & 6.97 \\
Buxtonella spp. & 13 & 1.81 \\
Cryptosporidium spp. & & \\
Helminths & 31 & 4.32 \\
Strongylus spp. & 59 & 8.23 \\
Marshallagia spp. & 38 & 5.30 \\
Nematodirus spp. & 16 & 2.23 \\
Trichuris spp. & 6 & 0.84 \\
Bunostomum-like spp. & 80 & 11.16 \\
Strongyloides spp. & 4 & 0.56 \\
Oesophagostomum spp. & 4 & 0.56 \\
Trichostrongylus spp. & 4 & 0.56 \\
Dictyocaulus spp. & 3 & 0.42 \\
Chabertia spp. & 3 & 0.42 \\
Ostertagia spp. & 2 & 0.28 \\
Cooperia spp. & 31 & 4.32 \\
Moniezia spp. & 3 & 0.42 \\
Fasciola spp. & & \\
\hline
\end{tabular}

that the overall infection rate was $48.26 \%$ (346/717) of investigated camels at Steppe and Northern Sahara regions of Algeria. These findings are in agreement with those reported previously from different African and Asian countries [6,21-23]. It is worth mentioning that parasitic infections of camels are likely to depend on environmental and host-related factors. Climatic conditions and husbandry practices are important environmental factors, whereas, animal breed, age, and population density are host-related factors. Furthermore, investigation method, sampling time, and number of screened animals are important ones. These factors may have individually or collectively contributed to the high infection rate recorded in the present study.
The results of the present study indicated that helminthic infections were $(170 / 717 ; 23.71 \%)$ compared to protozoan infections $(122 / 717 ; 17.02 \%)$ in the investigated camels. These findings are similar to those reported in the previous studies $[22,24]$. It is evident that the helminthic and protozoan infections are commonly associated with livestock, including camels.

No statistical differences were found between different age categories and excretion of endoparasites detective stage, contrasting results reported by Bekele [6] state that parasite excretion was more recorded in adult animals compared to young ones. In concordance with Radfar and Aminzadeh [22], no significant difference was recorded in parasitic excretion and the sex of the camel. Contrariwise, it has been reported that the females were more prone to parasitic infection than males [6,21]. Noteworthy, the breed of camels had no influence on the occurrence of infection, the implication of this factor in the excretion of internal parasites is poorly known, and so further studies are needed to clarify this situation.

Despite the low number of investigated diarrheic camels $(20 / 717)$ in the present survey, the infection rate in these camels $(9 / 20)$ did not differ from that in non-diarrheic ones. Although it is difficult to explain the causes of diarrhea in camels, nutritional factors and/or gastrointestinal infections are important elements. Furthermore, the load of infectious parasites play a crucial role in instigating diarrhea $[5,25]$.

The results of the present study identified diverse genera of nematodes and protozoans recorded in investigated camels (Table-5), with Strongyloides spp. and Eimeria spp. were the most prevalent parasites, which was not the case in several studies [21-23]. Meanwhile, Oesophagostomum spp., Trichostrongylus spp., Dictyocaulus spp., Chabertia spp., Ostertagia spp., Cooperia spp., and Fasciola spp. were observed with the lower prevalence. In general, the findings of the present study regarding the infection rate of each detected genre are lower compared to those reported previously from different African and Asian countries.

It is worth noting that the prevalence of cryptosporidiosis in Algerian dromedary camel has been scarcely dealt with. Only two previous Algerian studies reported a prevalence of 5.13\% [16] and 2.01\% [17]. The prevalence of the present study $(1.81 \%)$ is slightly lower than those reported in Algeria and even in Egypt (3.4\%) [26]. However, our prevalence is similar to that from Iran (1.9\%) [7], whereas, it is significantly very low when compared to results from other some previous studies conducted in Iran (37.9\%) and in Iraq $(61 \%)[27,28]$.

The age group of camels has a significant effect on the presence of cryptosporidiosis infection that is observed in the present report as well as conducted in several other studies [26,28,29]. Notwithstanding, no statistical difference was found between the age of camels and the presence of Cryptosporidium spp. 
in some Iranian reports [5,27]. The area of origin (steppe and Sahara), sex, breed, and diarrheal status was not reported as an associated risk factors in the prevalence variation of Cryptosporidium spp. A little is known concerning the zoonotic potential of dromedary camel cryptosporidiosis. C. parvum, C. andersoni, Cryptosporidium rat genotype IV, and a novel genotype (named "camel genotype") are known to infect dromedary camel [30]. Only C. parvum (subtype IIaA17G2R1) that detected in dromedary camel represents a common zoonotic subtype reported in humans and animals worldwide [31]. In addition to Cryptosporidium parvum, dromedary camel can play a role as potential reservoir of major zoonotic parasites transmitted to humans through direct/indirect contamination such as Giardia duodenalis, Blastocystis spp. and Enterocytozoon bieneusi, as food-borne infections such as Toxoplasma gondii and Trichinella spp., and by arthropod vectors including Trypanosoma spp [30]. Some parasites common to ruminants and camels like Trichostrongylus have minor public health significance and can occasionally infect human. Among more than 30 species within Trichostrongylus genus, ten different species have been reported in humans including $T$. colubriformis that representing the main zoonotic species $[32,33]$. The morphology of Cryptosporidium oocysts and Trichostrongylus eggs does not allow anyway the differentiation between the different species within these two parasite genus. Therefore, in the present study, molecular analysis is required for species identification and highlighting of their zoonotic potential.

\section{Conclusion}

The parasite fauna infecting the gastrointestinal tract of the Algerian dromedary is much diversified, consisting of different species of helminths and protozoa, common to other ruminants. They can affect the growth and productivity of animals and cause clinical signs of diarrhea as well. Future studies should be carried out to better understand the epidemiology of these parasitic diseases and investigate their economic and public health impact.

\section{Authors' Contributions}

$\mathrm{MB}, \mathrm{FEC}$, and AKL collected the samples and did the laboratory analysis. MB carried out the statistical analysis and data curation. $\mathrm{AH}$ and $\mathrm{KH}$ designed the study and laboratory work. AKL and MB wrote the manuscript. DB and $\mathrm{AH}$ helped in the writing and review. All authors have read and approved the final manuscript.

\section{Acknowledgments}

The authors thank Dr. Alireza Sazmand for his help in parasite identification, Dr. Hachelaf Ahmed Abdelhakim, and Pr. Said Amer (May God have mercy on him) for the proofreading. The authors would also like to extend immense thanks the owners of camel herds for their collaboration, patience, and utmost generosity. The authors did not receive any funds for this work.

\section{Competing Interests}

The authors declare that they have no competing interests.

\section{Publisher's Note}

Veterinary World remains neutral with regard to jurisdictional claims in published map and institutional affiliation.

\section{References}

1. Ahmed, M.E., Hassan, O.A., Khalifa, A.K.A., Elobied, E., Osman, A.A.A., Brair, S.L., Ahmed, O.I.E., Elfadul, M.M.A., Cremers, A.L. and Grobusch, M.P. (2018) Echinococcosis in Tambool, Central Sudan: A knowledge, attitude and practice (KAP) study. Int. Health, 10(6): 490-494.

2. Dubey, J.P. and Schuster, R.K. (2018) A review of coccidiosis in old world camels. Vet. Parasitol., 262: 75-83.

3. Oksanen, A. and Lavikainen, A. (2015) Echinococcus canadensis transmission in the North. Vet. Parasitol., 213(3-4): 182-186.

4. Saeed, M.A., Vaughan, J.L. and Jabbar, A. (2018) An update on sarcocystosis in one-humped camels (Camelus dromedarius). Parasitology, 145(11): 1367-1377.

5. Sazmand, A. and Joachim, A. (2017) Parasitic diseases of camels in Iran (1931-2017)-a literature review. Parasite, 24: 21 .

6. Bekele, T. (2002) Epidemiological studies on gastrointestinal helminths of dromedary (Camelus dromedarius) in semi-arid lands of Eastern Ethiopia. Vet. Parasitol., 105(2): 139-152.

7. Borji, H., Razmi, G., Movassaghi, A.R., Naghibi, A. and Maleki, M. (2009) Prevalence of Cryptosporidium and Eimeria infections in dromedary (Camelus dromedarius) in abattoir, Iran. J. Camel. Practice. Res., 16(2): 167-170.

8. Metwally, D.M., Qassim, L.E., Al-Turaiki, I.M., Almeer, R.S. and El-Khadragy, M.F. (2018) Gene based molecular analysis of COX1 in Echinococcus granulosus cysts isolated from naturally infected livestock in Riyadh, Saudi Arabia. PLoS One, 13(4): e0195016.

9. Mirzaei, M., Ghahvei, Y., Lefoulon, E., Lia, R.P., Otranto, D., Martin, C. and Sazmand, A. (2018) Morphological and molecular characterization of Onchocerca fasciata (Nematoda, Onchocercidae) from dromedary camels (Camelus dromedarius) in Iran. Parasite, 25: 50.

10. Narnaware, S.D., Kumar, S., Dahiya, S.S. and Patil, N.V. (2017) Concurrent infection of coccidiosis and haemonchosis in a dromedary camel calf from Rajasthan, India. $J$. Camel. Practice. Res., 24(3): 225-228.

11. Bennoune, O., Adili, N., Amri, K., Bennecib, L. and Ayachi, A. (2013) Trypanosomiasis of camels (Camelus dromedarius) in Algeria: First report. Vet. Res. Forum., 4(4): 273-275.

12. Bouhous, A., Aissi, M. and Harhoura, K.H. (2008) Study of Ixodidae in dromedaries in Southern Algeria, Adrar region (in French). Ann. Méd. Vét., 152(1): 52-58.

13. Djerbouh, A., Kernif, T., Beneldjouzi, A., Socolovschi, C., Kechemir, N., Parola, P., Raoult, D. and Bitam, I. (2012) The first molecular detection of Rickettsia aeschlimannii in the ticks of camels from Southern Algeria. Ticks. Tick. Borne. Dis., 3(5-6): 374-375.

14. Maillard, S., Benchikh-Elfegoun, M.C., Knapp, J., Bart, J.M., Koskei, P., Gottstein, B. and Piarroux, R. (2007) Taxonomic position and geographical distribution of the common sheep G1 and camel G6 strains of Echinococcus 
granulosus in three African countries. Parasitol. Res., 100(3): 495-503.

15. Zait, H., Kouidri, M., Grenouillet, F.E., Umhang, G., Millon, L., Hamrioui, B. and Grenouillet, F. (2016) Molecular characterization of Echinococcus granulosus sensu stricto and Echinococcus canadensis in humans and livestock from Algeria. Parasitol. Res., 115(6): 2423-2431.

16. Baroudi, D., Zhang, H., Amer, S., Khelef, D., Roellig, D., Wang, Y., Feng, Y. and Xiao, L. (2018) Divergent Cryptosporidium parvum subtype and Enterocytozoon bieneusi genotypes in dromedary camels in Algeria. Parasitol. Res., 117(3): 905-910.

17. Laatamna, A.K., Belkessa, S., Khalil, A., Afidi, A., Benmahdjouba, K., Belalmi, R., Benkrour, M., Ghazel, Z., Hakem,A. and Aissi, M.(2018) Prevalence of Cryptosporidium spp. in farmed animals from steppe and high plateau regions in Algeria. Trop. Biomed., 35(3): 724-735.

18. Allen, V.H. and Ridley, D.S. (1970) Further observations on the formol-ether concentration technique for fecal parasites. J. Clin. Pathol., 23(6): 545-546.

19. Henriksen, S.A. and Pohlenz, J.F. (1981) Staining of cryptosporidia by a modified Ziehl-Neelsen technique. Acta. Vet. Scand., 22(3-4): 594-596.

20. OIE-World Organization for Animal Health. Manual of diagnostic tests and vaccines for terrestrial animals (mammals, birds and bees). Seventh Edition (volume 2), 2012.

21. Abdel-Rady, A. (2014) Epidemiological studies on parasitic infestations in camels (Camelus dromedaries) in Egypt. Eur. J. Environ. Ecol., 1(1): 16-20.

22. Radfar, M.H. and Aminzadeh, G.M. (2013) Common gastrointestinal parasites of indigenous camels (Camelus dromedarius) with traditional husbandry management (free ranging system) in central deserts of Iran. J. Parasit. Dis., 37(2): 225-230.

23. Borji, H., Razmi, G., Movassaghi, A.R., Naghibi, A. and Maleki, M. (2010) A study on gastro-intestinal helminths of camels in Mashhad abattoir, Iran. Iran. J. Vet. Res., 11(2): 174-179.
24. Anwar, A.H. and Khan, M.N. (1998) Parasitic Fauna of Camel in Pakistan. Proceedings of the $3^{\text {rd }}$ Annual Meeting for Animal Production Under Arid Conditions, United Arab Emirates. p69-76.

25. Parsani, H.R., Singh, V. and Momin, R.R. (2008) Common parasitic diseases of camel. Vet. World, 1(10): 317-318.

26. Saleh, M.A. and Mahran, O.M. (2007) A preliminary study on cryptosporidiosis in dromedary camels at Shalatin Area, Egypt. Assiut. Vet. Med. J., 53(112): 195-208.

27. Razawi, S.M., Oryan, A., Bahrami, S., Mohammadalipour, A. and Gowhari, M. (2009) Prevalence of Cryptosporidium infection in camels (Camelus dromedarius) in a slaughterhouse in Iran. Trop. Biomed., 26(3): 267-273.

28. Hussin, A.G., Khalaf, J.M. and Ali, H.M. (2015) Detection of intestinal protozoa in camels and their breeders in Najef, Iraq. Res. J. Vet. Pract., 3(3): 53-57.

29. Yakhchali, M. and Moradi, T. (2012) Prevalence of Cryptosporidium-like infection in one-humped camels (Camelus dromedarius) of North Western Iran. Parasite, 19(1): 71-75.

30. Sazmand, A., Joachim, A. and Otranto, D. (2019) Zoonotic parasites of dromedary camels: So important, so ignored. Parasit. Vectors, 12(1): 610.

31. Zahdi, A., Lee, G.K.C., Greay, T.L., Walsh, A.L., Blignaut, D.J.C. and Ryan, U.M. (2018) First report of Cryptosporidium parvum in a dromedary camel calf from Western Australia. Acta. Parasitol., 63(2): 422-427.

32. Sato, M., Yoonuan, T., Sanguankiat, S., Nuamtanong, S., Pongvongsa, T., Phimmayoi, I., Phanhanan, V., Boupha, B., Moji, K. and Waikagul, J. (2011) Human Trichostrongylus colubriformis infection in a rural village in Laos. Am. J. Trop. Med. Hyg., 84(1): 52-54.

33. Gholami, S., Babamahmoodi, F., Abedian, R., Sharif, M., Shahbazi, A., Pagheh, A. and Fakhar, M. (2015) Trichostrongylus colubriformis: Possible most common cause of human infection in Mazandaran Province, North of Iran. Iran J. Parasitol., 10(1): 110-115. 